\title{
Radiative Performance of Rare Earth Garnet Thin Film Selective Emitters
}

\author{
Roland A. Lowe*, Donald L. Chubb ${ }^{+}$and Brian S. Good ${ }^{+}$ \\ * Kent State University, Kent, Ohio 44242 \\ + NASA Lewis Research Center, Cleveland, Ohio 44135
}

\begin{abstract}
In this paper we present the first emitter efficiency results for the thin film $40 \%$ Er-1.5\% Ho YAG (Y trium Aluminum Garnet, $\mathrm{Y}_{3} \mathrm{Al}_{5} \mathrm{O}_{12}$ ) and 25\% Ho YAG selective emitter at $1500 \mathrm{~K}$ with a platinum substrate. Spectral emittance and emissive power measurements were made $(1.2<\lambda<3.2 \mu \mathrm{m})$. Emitter efficiency and power density are significantly improved with the addition of multiple rare earth dopants. Predicted efficiency results are presented for an optimized (equal power density in the $\mathrm{Er},{ }^{4} \mathrm{I}_{15 / 2}-{ }^{4} \mathrm{I}_{13 / 2} @ 1.5 \mu \mathrm{m}$, and Ho, $\mathrm{SI}_{7}-\mathrm{SI}_{8} @ 2.0 \mu \mathrm{m}$ emission bands) Er-Ho YAG thin film selective emitter.
\end{abstract}

\section{INTRODUCTION}

Efficient thermophotovoltaic (TPV) energy conversion is strongly dependent on emitter performance ${ }^{1}$. The most promising solid state selective emitters are compounds containing elements in the Lanthanide Series (rare earths). Nelson and Parent $2,3,4$ using the rare earth oxide Welsbach mantle emitter have been the most successful. A new class of rare earth solid state selective emitters, the rare earth garnets 5 , has the potential for being efficient, as well as, more durable than the mantle type emitter. In this paper we present the emitter efficiency results for the thin film YAG (Yttrium Aluminum Garnet, $\mathrm{Y}_{3} \mathrm{Al}_{5} \mathrm{O}_{12}$ ) doped with holmium and erbium.

\section{RARE EARTH GARNET SELECTIVE EMITTER}

The atomic structure of the doubly and triply charged rare earth ions such as $\mathrm{Yb}, \mathrm{Er}, \mathrm{Ho}, \mathrm{Tm}, \mathrm{Dy}$, and $\mathrm{Nd}$ accounts for their unique spectral emission characteristics. The orbits of the valence $4 \mathrm{f}$ electrons, whose electronic transitions determine the spectral emission properties, lie inside the $5 \mathrm{~s}$ and $5 \mathrm{p}$ electron orbits. The $5 s$ and $5 p$ electrons "shield" the $4 \mathrm{f}$ valence electrons from the surrounding ions in the crystal. As a result, the rare earth ions in the solid state have radiative characteristics much like if they were an isolated atom in a gas and emit in relatively narrow bands rather than in a continuum as do most solids.

As already mentioned, the first successful rare earth selective emitters were the rare earth oxides. Recently rare earth doped YAG has shown excellent emissive properties 5 . Doping limits, dependent on the particular ion and crystal host may be

*NASA Resident Research Associate at Lewis Research Center. 
as high as 100 at. \% (complete substitution of the yttrium ion with the rare earth ion). These materials have high melting points (1940 C for undoped YAG) making them excellent candidates for a high temperature thin film selective emitter. For most of the rare earths the emission spectra is dominated by a single emission band in the near infrared $(0.9<\lambda<3.0 \mu \mathrm{m})$ with low emission outside this band. Since YAG can be doped with more than a single rare earth it is possible to make a thin film selective emitter with multiple emission bands. As a result, greater power density over a wider wavelength interval can be achieved than with a single rare earth dopant.

The efficiency, $\eta_{E}$, of a selective emitter is defined as

$$
\eta_{E}=\frac{Q_{b}}{Q_{T}}
$$

where $\mathrm{Q}_{\mathrm{b}}$ is the emitted power in the emission band and $\mathrm{Q}_{\mathrm{T}}$ is the total emitted power. Also

$$
\begin{aligned}
& Q_{b}=\int_{\lambda_{u}}^{\lambda_{1}} q_{\lambda} d \lambda \\
& Q_{T}=\int_{0}^{\infty} q_{\lambda} d \lambda
\end{aligned}
$$

where $q_{\lambda}$ is the spectral emissive power of the emitter, $\lambda_{u}$ is the short wavelength limit for the emission band and $\lambda_{1}$ is the long wavelength limit for the emission band. In the experiment to be described in the next section $q_{\lambda}$ is measured with a spectroradiometer and $\mathrm{Q}_{\mathrm{b}}$ and $\mathrm{Q}_{\mathrm{T}}$ are measured with a pyroelectric radiometer.

\section{Experimental Procedure}

Quantities such as emissivity and absorptivity are usually thought of as properties of an isothermal surface. However, for the thin film rare-earth YAG emitter emission from throughout the film contributes to the spectral emittance. Since significant temperature gradients $(230 \mathrm{~K})$ exist between the front and back emitter surfaces the "emitter temperature", used to calculate emittance from the intensity measurements, is not a surface temperature but rather the average of the front and back surface temperatures, $\mathrm{T}_{\mathrm{Eavg}}$ in the center of the sample. A radial temperature gradient of $5 \mathrm{~K}$ was also measured on the sample in the field of view of the pyroelectric radiometer. This variation, small in comparison to the front-back temperature gradient and other sources of experimental error, was neglected in the emittance calculations. Temperature measurements, made with type $R$ thermocouples, had an accuracy of $+/-6 \mathrm{~K}$. Total power and power in the Ho YAG 
emission band was measured with a Laser Precision Rk-5100 radiometer calibrated to an NBS traceable standard. Normal spectral emittance, $\varepsilon_{\lambda}$, measurements were made with a spectroradiometer constructed from a $1 / 8$ meter monochrometer, a temperature controlled $\mathrm{PbS}$ detector, and an $800 \mathrm{~Hz}$ chopper calibrated with a 1270 $\mathrm{K}$ blackbody reference. Energy in the emission band, $\mathrm{Q}_{b}$, is measured with the spectroradiometer and calculated using eq. 2. Normal spectral emittance measurement accuracy and repeatability with the blackbody reference at $1270 \mathrm{~K}$ was typically within $2 \%$ from $1.2<\lambda<3.2 \mu \mathrm{m}$. A series of precision optical pinholes was used to limit the field of view at the specimen surface for both the spectroradiometer and the pyroelectric radiometer. Custom software developed with LabView for the Macintosh was used to calculate spectral emittance and emissive power, and emitted power/wavelength-interval from the intensity measurements.

Specimens were cut from Czochralski grown crystals and polished on both sides with $1 \mu$ diamond abrasive. Platinum foil was placed behind the samples as a low emittance substrate. The configuration shown in fig. 1 was used to eliminate

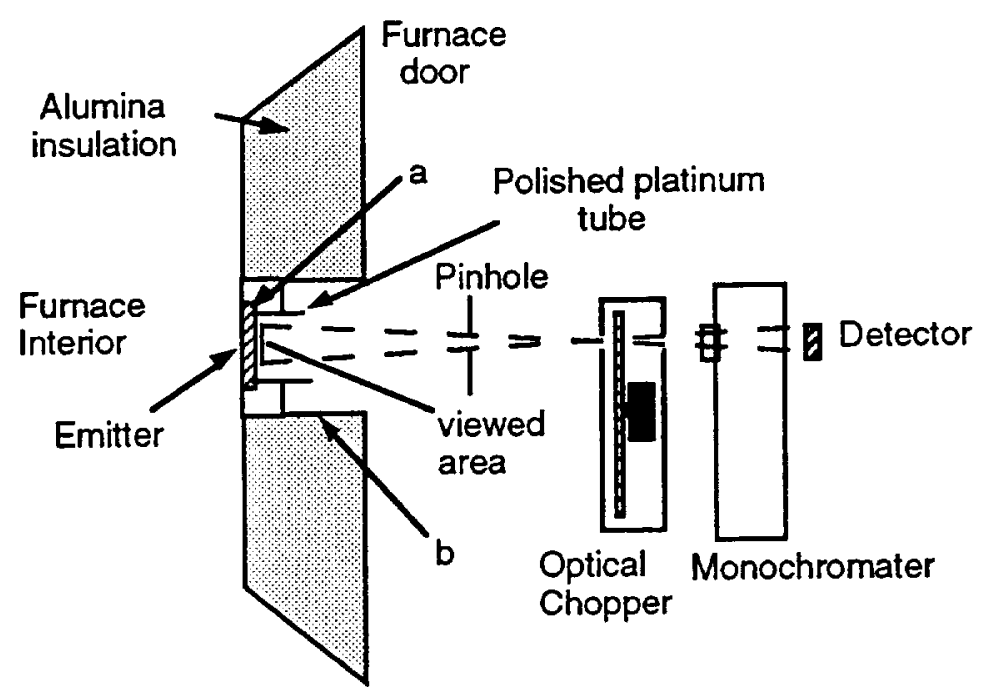

FIGURE 1. Schematic diagram of experimental setup

reflected radiation from the furnace interior, a near blackbody radiator, from reaching the detector. Two sources of measurement error were identified. Alumina insulation, a nearly perfect diffuse reflector, reflects radiation originating from the perimeter of the sample (a), which is at a higher temperature than the viewed area, to the surface of the sample in the field of view of the detector. Also, emission from the hot alumina (b) is reflected directly from the viewed area to the detector. A polished (specular) platinum tube was inserted in the hole through the insulation near the specimen to reduce the measurement error from these combined effects. Comparison of $\varepsilon_{\lambda}$ measurements of polished platinum foil at $1648 \mathrm{~K}$ and data from ref. 6 show the increase in $\varepsilon_{\lambda}$ due to reflected radiation and temperature measurement error is $+0.06 @ 2.0 \mu \mathrm{m}$ and $+0.07 @ 1.5 \mu \mathrm{m}$. This will be the 
maximum measurement error for materials with high spectral reflectance ( $\sim 80 \%)$ and low emittance such as platinum. However, in the Ho and Er-YAG specimens, reflectance in the emission band is less (20-70\% for Ho-YAG) and the actual measurement error will be lower than the error for platinum.

\section{Efficiency Results}

Thin film selective emitter performance is dependent on factors such as emitter thickness and temperature, substrate emittance ${ }^{7}$ and rare earth dopant type and concentration. For maximum emitter performance it is essential that these parameters be optimized. The experimental results presented here for the $\mathrm{Ho}$ and $\mathrm{Er}$ YAG thin film selective emitters do not include efforts to maximize performance through optimization of these parameters. The test temperature $(1500 \mathrm{~K})$ is high enough to produce reasonable emission levels for optical detection but is too low to achieve the maximum predicted efficiency for Ho $(1800 \mathrm{~K})$ and $\mathrm{Er}(2400 \mathrm{~K})$ emitters. The thickness and doping level of the test specimens reflects the commercial availability of material developed for solid state lasers. Even without optimization results indicate that rare earth thin film selective emitters have potential as elements in a high efficiency TPV system.

A co-doped Er-Ho YAG emitter was used to investigate the efficiency of $\mathrm{Er}$ YAG at $1500 \mathrm{~K}$. Since the Ho doping concentration, $1.5 \%$, and hence the emission at $2.0 \mu \mathrm{m}$, is significantly less then the Er doping concentration, $40 \%$, efficiency results are expected to be similar to that of the $40 \%$ Er YAG emitter in ref. 5. Fig. 2 shows the normal spectral emittance of a $40 \%$ Er-1.5\% Ho YAG emitter $1.5 \mathrm{~mm}$

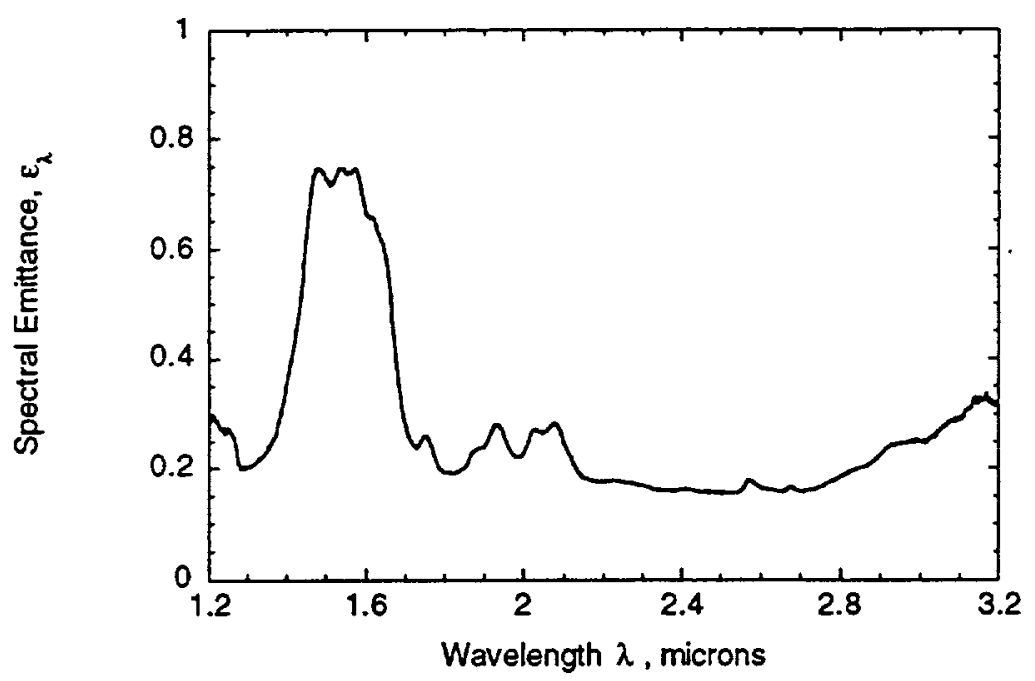

FIGURE 2. Spectral emittance of the $40 \% \mathrm{Er}-1.5 \%$ Ho YAG thin film selective emitter

thick at $1472 \mathrm{~K}$ from $1.2<\lambda<3.2 \mu \mathrm{m}$. Relatively strong emission is present at the 
characteristic laser transitions for Er YAG $\left({ }^{4} \mathrm{I}_{15 / 2}-{ }^{4} \mathrm{I}_{13 / 2} @ 1.5 \mu \mathrm{m}\right)$ and Ho YAG ( $\left.5 \mathrm{I}_{7}-{ }^{5} \mathrm{I}_{8} @ 2.0 \mu \mathrm{m}\right)$.

Several methods were used to calculate values for emitter efficiency using eq.1. First, the power in the Er emission band, $\mathrm{Q}_{\mathrm{b}}$, from $\lambda_{\mathrm{u}}=1.3$ to $\lambda_{1}=1.8 \mu \mathrm{m}$ is divided by the total measured power, $\mathrm{Q}_{\mathrm{T}}$. Second, the power in the Er and Ho emission bands from $\lambda_{u}=1.3$ to $\lambda_{1}=2.2 \mu \mathrm{m}$, is divided by the total measured power. Third, the power in the Er emission band, from $\lambda_{u}=1.3$ to $\lambda_{1}=1.8 \mu \mathrm{m}$, is divided by the total measured power reduced by the power in the Ho emission band. To estimate the power in the Ho emission band the integrated power using a constant emittance of 0.16 from 1.8 to $2.53 \mu \mathrm{m}$ @ $1472 \mathrm{~K}$ was subtracted from the integrated power over the same wavelength interval from the experimental results. The contribution of the Ho emission band to the total radiated power using this method is 0.26 watts $/ \mathrm{cm}^{2}$.

The normal spectral emittance of a $25 \%$ Ho YAG thin film selective emitter $0.65 \mathrm{~mm}$ thick@1477 K is shown in fig. 3. Two methods were used to calculate

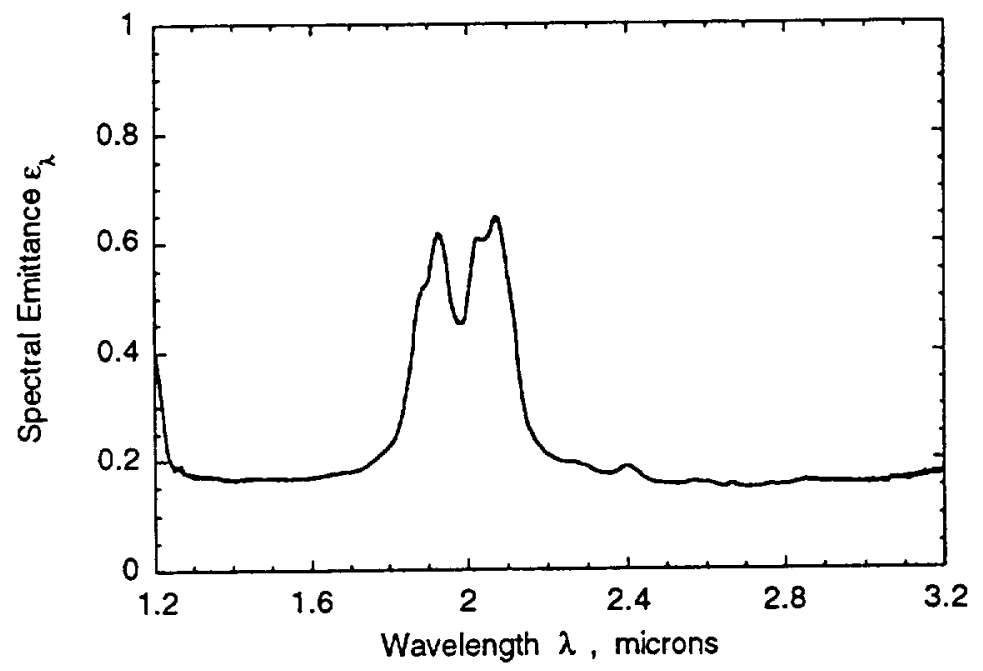

FIGURE 3. Spectral emittance of a $25 \%$ Ho YAG thin film selective emitter

the efficiency of this emitter. First, the power in the emission band, $\lambda_{u}=1.75$ to $\lambda_{1}$ $=2.2 \mu \mathrm{m}$, measured with the spectroradiometer is divided by the total measured power. Second, the power in the emission band, $\lambda_{u}=1.85$ to $\lambda_{1}=2.25 \mu \mathrm{m}$, is measured with an interference type bandpass filter and the pyroelectric radiometer and divided by the total measured power. Table 1 summarizes the results of the efficiency calculations for the Er-Ho and Ho YAG emitters.

The experimental results suggest that co-doping the emitter with more than one rare earth significantly improves the power density and radiative efficiency of the emitter. Using spectral emittance data for the Er-Ho and Ho emitters the spectral emissive power is calculated at $T_{\text {Eavg }}=1477 \mathrm{~K}$ and shown in fig. 4 simulating the 
TABLE I. Radiative Etficiency of the YAG Thin Film Selective Emitter

\begin{tabular}{lccccc}
\hline Type & $T_{E_{\text {avg }}}$ & Method & $Q_{b}$ (watts $\left./ \mathrm{cm}^{2}\right)$ & $Q_{T}$ (watts $\left./ \mathrm{cm}^{2}\right)$ & $\eta_{E}(\%)$ \\
\hline $40 \%$ Er - 1.5\% Ho & $1472 \mathrm{~K}$ & 1 & 1.74 & 9.33 & 18.7 \\
& & 2 & 2.55 & 9.33 & 27.3 \\
& & 3 & 1.74 & 9.07 & 19.2 \\
$25 \%$ Ho & \multirow{2}{*}{$1477 \mathrm{~K}$} & 1 & 1.72 & 9.75 & 17.7 \\
& & 2 & 1.92 & 9.75 & 19.7
\end{tabular}

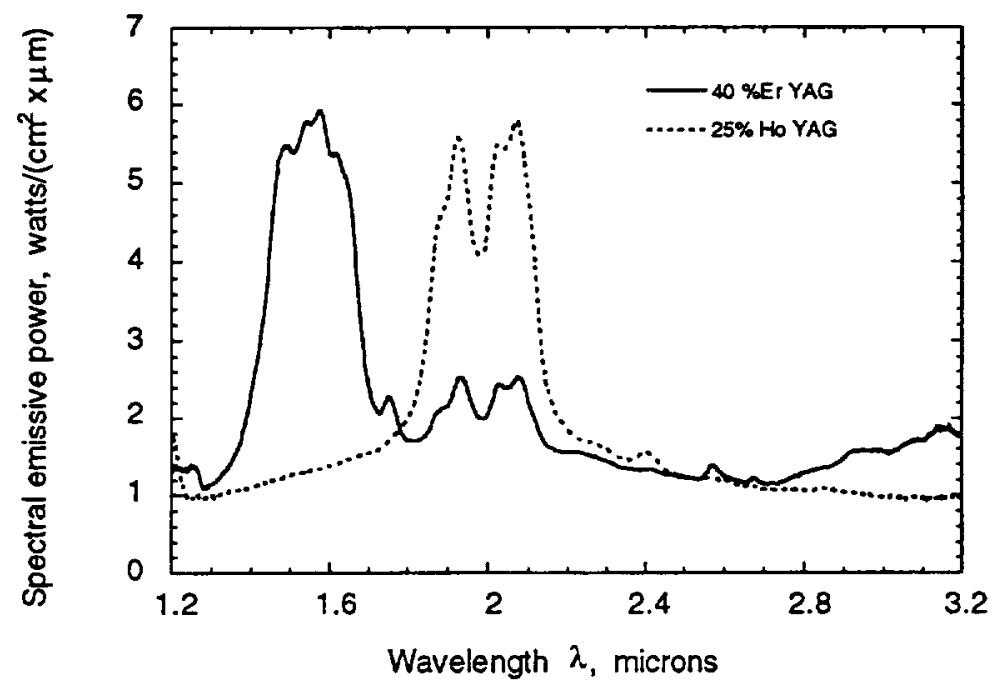

FIGURE 4. Spectral emissive power of an optimized Er-Ho YAG emitter

performance of an "optimized" $\mathrm{Er}$ - Ho emitter. Using the combined power in $\mathrm{Er}$ emission band, $\mathrm{Q}_{\mathrm{Er}}=1.75$ watts $/ \mathrm{cm}^{2}\left(\lambda_{\mathrm{u}}=1.3, \lambda_{1}=1.78 \mu \mathrm{m}\right)$, and Ho emission band, $\mathrm{Q}_{\mathrm{Ho}}=1.67$ watts $/ \mathrm{cm}^{2}\left(\lambda_{\mathrm{u}}=1.78, \lambda_{1}=2.2 \mu \mathrm{m}\right)$, the total power in the emission band $\mathrm{Q}_{\mathrm{b}}=3.42$ watts $/ \mathrm{cm}^{2}$. To estimate $\mathrm{Q}_{\mathrm{T}}$, the contribution of the $\mathrm{Er}$ emission band, $\mathrm{Q}_{\mathrm{Er}}$ minus the integrated power from 1.3 to $1.78 \mu \mathrm{m}$ assuming a emitter is estimated to be constant emittance of 0.16 , is added to the total power of the Ho YAG emitter, and $\mathrm{Q}_{\mathrm{T}}=10.9$ watts $/ \mathrm{cm}^{2}$. As a result, the efficiency of an "optimized" Er-Ho thin film selective is $31.4 \%$.

Further improvement in emitter efficiency may also be achieved by reducing the front-back emitter temperature gradient. Since the extinction coefficient for rare earth doped YAG is relatively low outside the emission band $\left(\sim 0.2 \mathrm{~cm}^{-1}\right)$ the emission in this region is dominated by the platinum substrate. Reducing the temperature gradient, with the back surface temperature constant, will increase $Q_{b}$ while the emission from the substrate remains constant, improving $8 \eta_{E}$. In this 
experiment convection loss contributes to the large emitter temperature gradient. Operating the emitter with a front surface vacuum interface would eliminate this loss, reduce the temperature gradient, and improve $\eta_{\mathrm{E}}$.

\section{CONCLUSION}

The first measured results for the "non optimized" emitter efficiency of rare earth YAG thin film selective emitters show that the emitter efficiency may be low, evenwith high emittance in the emission band $(-0.7)$ and low out of band emittance $(\sim 0.15)$, if the emission band is relatively narrow. Multiple emission bands from additional rare earth species in the emitter material increase the overall emission band width significantly improving emitter efficiency and usable power density. Additional improvements in efficiency and power density should also be possible through optimization of emitter film thickness and temperature, rare earth doping level, and reducing the emitter temperature gradient.

\section{REFERENCES}

1. Chubb D.L., "Reappraisal of Solid Selective Emitters", in Proceedings of the 21st Photovoltaic Specialists Conference IEEE, New York 1990 pp 1326-1342, also NASA TM103290, 1990

2. Nelson R.E., in Proceedings of the 32nd International Power Sources Symposium, Electrochemical Society, Pennington, NJ, 1986 pp 95-101

3. Parent C.R. and Nelson R.E., in Proceedings of the Twenty First Intersociety Energy Conversion Engineering Conferences, American Chemical Society, Washington DC, 1986 vol. 2, pp 1314-1317

4. Nelson R.E. and Iles P.A., "Space Solar Power for Orbital and Lunar Missions", ASME/ASES/SOLTECH Joint Solar Energy Conference, 1993

5. Lowe R.A., Chubb D.L., Farmer S.C. and Good B.S., Appl Phys. Letters, 64, 3551 1994)

6. Touloukian Y.S. and Ho C.Y., Thermophysical Properties of Matter vol. 7 "Thermal Radiative Properties Metallic Elements \& Alloys", (IFI/Plenum, New York, 1970, p. 542 (curve 24)

7. Chubb D.L. and Lowe R.A., J. Appl Phys, 74, (1993)

8. Good B.S., Chubb D.L. and Lowe R.A.,"Temperature-Dependent Efficiency Calculations foe a Thin Film Selective Emitter", in First NREL Conference on Thermophotovoltaic Generation of Electricity, American Institue of Physics, AIP Press, Woodbury NY, 1994 


\section{REPORT DOCUMENTATION PAGE}

Public reporting burden for this collection of information is estimated to average 1 hour per response, including the time for reviewing instructions, searching existing data sources, gathering and maintaining the data needed, and completing and reviewing the collection of information. Send comments regarding this burden estimate or any other aspect of this collection of information, including suggestions for reducing this burden, to Washington Headquarters Services, Directorate for Information Operations and Feports, 1215 Jetferson Davis Highway, Suite 1204, Arlington, VA 22202.4302, and to the Office of Management and Budget, Paperwork Reduction Project (0704-0188), Washington, DC 20503.

\begin{tabular}{|l|l|l|}
\hline 1. AGENCY USE ONLY (Leave blank) & $\begin{array}{r}\text { 2. REPORT DATE } \\
\text { August } 1994\end{array}$ & $\begin{array}{r}\text { 3. REPORT TYPE AND DATES COVERED } \\
\text { Technical Memorandum }\end{array}$ \\
\hline
\end{tabular}

4. TITLE AND SUBTITLE

Radiative Performance of Rare Earth Garnet Thin Film Selective Emitters

6. AUTHOR(S)

Roland A. Lowe, Donald L. Chubb, and Brian S. Good
5. FUNDING NUMBERS

WU-233-01-0A

\section{PERFORMING ORGANIZATION NAME(S) AND ADDRESS(ES)}

National Aeronautics and Space Administration

Lewis Research Center

Cleveland, Ohio 44135-3191
8. PERforming organization REPORT NUMBER

E-9088

9. SPONSORINGMONITORING AGENCY NAME(S) AND ADDRESS(ES)

10. SPONSORINGMONITORING AGENCY REPORT NUMBER

National Aeronautics and Space Administration

Washington, D.C. 20546-0001

NASA TM-106722

11. SUPPLEMENTARY NOTES

Prepared for the First Conference on Thermophotovoltaic Generation of Electricity sponsored by the National Renewable Energy Lab, Copper Mountain, Colorado, July 24-26, 1994. Roland A. Lowe, Kent State University, Kent, Ohio, and NASA Resident Research Associate at Lewis Research Center; Donald L. Chubb and Brian S. Good, NASA Lewis Research Center. Responsible person, Roland A. Lowe, organization code 5410, (216) 433-2226.

12a. DISTRIBUTIONAVAILABILITY STATEMENT

Unclassified - Unlimited

Subject Categories 44 and 76

13. ABSTRACT (Maximum 200 words)

In this paper we present the first emitter efficiency results for the thin film $40 \%$ Er-1.5\% Ho YAG (Yttrium Aluminum Garnet, $\mathrm{Y}_{3} \mathrm{Al}_{5} \mathrm{O}_{12}$ ) and $25 \%$ Ho YAG selective emitter at $1500 \mathrm{~K}$ with a platinum substrate. Spectral emittance and emissive power measurements were made $(1.2<\lambda<3.2 \mu \mathrm{m})$. Emitter efficiency and power density are significantly improved with the addition of multiple rare earth dopants. Predicted efficiency results are presented for an optimized (equal power density in the $\mathrm{Er}^{4}{ }^{4} \mathrm{I}_{15 / 2}-{ }^{4} \mathrm{I}_{13 / 2} @ 1.5 \mu \mathrm{m}$, and Ho, ${ }^{5} \mathrm{I}_{7}-{ }^{5} \mathrm{I}_{8} @ 2.0 \mu \mathrm{m}$ emission bands) Er-Ho YAG thin film selective emitter.

\section{SUBJECT TERMS}

TPV; Thermophotovoltaic; Selective emitter

17. SECURITY CLASSIFICATION OF REPORT

Unclassified
18. SECURITY CLASSIFICATION OF THIS PAGE Unclassified
19. SECURITY CLASSIFICATION OF ABSTRACT Unclassified
15. NUMBER OF PAGES

9

16. PRICE CODE

$\mathrm{AO} 2$

20. LIMITATION OF ABSTRACT

